\title{
ICA of fMRI studies: new approaches and cutting edge applications
}

\author{
Simon Daniel Robinson ${ }^{1 *}$ and Veronika Schöpf ${ }^{2}$ \\ 1 High Field MR Centre, Department of Biomedical Imaging and Image-guided Therapy, Medical University of Vienna, Vienna, Austria \\ 2 Department of Biomedical Imaging and Image-guided Therapy, Medical University of Vienna, Vienna, Austria \\ ${ }^{*}$ Correspondence: simon.robinson@meduniwien.ac.at
}

Edited by:

Hauke R. Heekeren, Freie Universität Berlin, Germany

Keywords: independent component analysis, functional magnetic resonance imaging, resting-state networks, schizophrenia, presurgical planning, real-time fMRI, ultra-high field, multiband EPI

Independent component analysis (ICA) is the most commonly used and most diversely applicable exploratory method for the analysis of functional magnetic resonance imaging (fMRI) data. Over the last 10 years it has offered a wealth of insights into brain function during task execution and in the resting state.

Independent component analysis is a blind source separation method that was originally applied to identify technical and physiological artifacts in $\mathrm{fMRI}$, and to allow their removal prior to analysis with model-based approaches. It has matured into a method capable of offering a stand-alone assessment of activation on a sound statistical footing. Recent innovations have taken on the challenges of how components should be combined over subjects to allow group inferences, and how activation identified with ICA might be compared between groups - of patients and controls - for instance. Its reputation having been bolstered by multiple successes in the investigation of resting-state networks, ICA is being applied in other cutting edge uses of fMRI; in multivariate pattern analysis, real-time fMRI, in utero studies, with a wide variety of paradigms and stimulus types and with challenging tasks with patients at ultra-high field. These are testament both to ICA's flexibility and its evolving role both in basic neuroscience and clinical applications of fMRI.

This Research Topic has attracted 19 contributions from the most renowned researchers in the field, including the inventor of Fast ICA, Aapo Hyvärinen (Hyvärinen and Ramkumar, 2013), and the authors of the most widely used ICA software for fMRI Christian Beckmann (FSL's MELODIC) and Vince Calhoun (GIFT). The capacity of ICA to find common patterns of activation in huge cohorts of subjects is demonstrated by the parallel computing approach described by Kalcher et al. (2012) and the use of ICA with cutting edge MR methods are presented by the groups of Stefan Posse [Echo Volume Imaging (Posse et al., 2013)], Markus Barth [EEG-fMRI (Meyer et al., 2013) and Ultra-Fast Generalized Inverse Imaging (Boyacioglu et al., 2013)], and Jorge Jovicich [realtime fMRI (Soldati et al., 2013a,b)].

Two articles in this research topic reflect the continued use of ICA to identify artifacts, using the temporal characteristics of components (Rummel et al., 2013) or both temporal and spatial features (Bhaganagarapu et al., 2013). In addition to using frequency signatures to identify noise, the frequencies of signal fluctuations during rest have been studied using temporal ICA (Boubela et al., 2013) and in ultra-fast generalized imaging (Boyacioglu et al., 2013), while Di et al. (2013) examine the influence of amplitude on resting-state connectivity and Balsters et al. (2013) assess the correlation between BOLD spectral power and working memory performance.

The ICA applications featured in this Research Topic range from clinical resting-state studies with patients suffering from schizophrenia (Manoliu et al., 2013; Sui et al., 2013) and neurological patients performing chin and hand motor tasks (Robinson et al., 2013) to the investigation of processing streams using chemosensory stimuli (Frasnelli et al., 2012). Combined methodological approaches are used to study belief decision making with fMRI and EEG (Douglas et al., 2013), to discriminate schizophrenia using data from fMRI, DTI, and sMRI (Sui et al., 2013), to identify amyotrophic lateral sclerosis diseased brains (Welsh et al., 2013) and to examine the microvascular specificity of the BOLD effect at 3 and 7 T using SWI (Geissler et al., 2013).

We hope this collection of original research articles illustrates the extent to which ICA is becoming an increasingly flexible and potent analysis method - particularly through innovations such as real-time ICA, temporal ICA, and parallel processing implementations - and that the capacity of ICA to isolate the underlying signal sources in fMRI data is being enhanced by multimodal and ultra-fast imaging. These innovations are leading to an increase in the utility of ICA and the richness of information it can provide in both basic research work and clinical applications.

\section{REFERENCES}

Balsters, J. H., Robertson, I. H., and Calhoun, V. D. (2013). BOLD frequency power indexes working memory performance. Front. Hum. Neurosci. 7:207. doi: 10.3389/ fnhum.2013.00207

Bhaganagarapu, K., Jackson, G. D., and Abbott, D. F. (2013). An automated method for identifying artifact in independent component analysis of resting-state fMRI Front. Hum. Neurosci. 7:343. doi: 10.3389/fnhum.2013.00343

Boubela, R. N., Kalcher, K., Huf, W., Kronnerwetter, C., Filzmoser, P., and Moser, E. (2013). Beyond noise: using temporal ICA to extract meaningful information from high-frequency fMRI signal fluctuations during rest. Front. Hum. Neurosci. 7:168. doi: 10.3389/fnhum.2013.00168

Boyacioglu, R., Beckmann, C. F., and Barth, M. (2013). An investigation of RSN fre quency spectra using ultra-fast generalized inverse imaging. Front. Hum. Neurosci. 7:156. doi: 10.3389/fnhum.2013.00156

Di, X., Kim, E. H., Huang, C.-C., Tsai, S.-J., Lin, C.-P., and Biswal, B. B. (2013). The influence of the amplitude of low-frequency fluctuations on resting-state functional connectivity. Front. Hum. Neurosci. 7:118. doi: 10.3389/fnhum.2013.00118

Douglas, P. K., Lau, E., Anderson, A., Head, A., Kerr, W., Wollner, M., et al. (2013). Single trial decoding of belief decision making from EEG and fMRI data using independent components features. Front. Hum. Neurosci. 7:392. doi: 10.3389/ fnhum.2013.00392 
Frasnelli, J., Lundström, J. N., Schöpf, V., Negoias, S., Hummel, T., and Lepore, F. (2012). Dual processing streams in chemosensory perception. Front. Hum. Neurosci. 6:288. doi: 10.3389/fnhum.2012.00288

Geißler, A., Fischmeister, F. PhS., Grabner, G., Wurnig, M., Rath, J., Foki, T., et al. (2013). Comparing the microvascular specificity of the 3- and 7-T BOLD response using ICA and susceptibility-weighted imaging. Front. Hum. Neurosci. 7:474. doi: 10.3389/ fnhum.2013.00474

Hyvärinen, A., and Ramkumar, P. (2013). Testing independent component patterns by inter-subject or inter-session consistency. Front. Hum. Neurosci. 7:94. doi: 10.3389/ fnhum.2013.00094

Kalcher, K., Huf, W., Boubela, R. N., Filzmoser, P., Pezawas, L., Biswal, B., et al. (2012). Fully exploratory network independent component analysis of the 1000 functional connectomes database. Front. Hum. Neurosci. 6:301. doi: 10.3389/ fnhum.2012.00301

Manoliu, A., Riedl, V., Doll, A., Bäuml, J. G., Mühlau, M., Schwerthöffer, D., et al. (2013). Insular dysfunction reflects altered between-network connectivity and severity of negative symptoms in schizophrenia during psychotic remission. Front. Hum. Neurosci. 7:216. doi: 10.3389/fnhum.2013.00216

Meyer, M. C., Janssen, R. J., Van Oort, E. S. B., Beckmann, C. F., and Barth, M. (2013). The quest for EEG power band correlation with ICA derived fMRI resting state networks. Front. Hum. Neurosci. 7:315. doi: 10.3389/fnhum.2013.00315

Posse, S., Ackley, E., Mutihac, R., Zhang, T., Hummatov, R., Akhtari, M., et al. (2013). High-speed real-time resting-state fMRI using multi-slab echo-volumar imaging. Front. Hum. Neurosci. 7:479. doi: 10.3389/fnhum.2013.00479

Robinson, S. D., Schöpf, V., Cardoso, P., Geissler, A., Fischmeister, F. PhS., Wurnig, M., et al. (2013). Applying independent component analysis to clinical fMRI at $7 \mathrm{~T}$. Front. Hum. Neurosci. 7:496. doi: 10.3389/fnhum.2013.00496
Rummel, C., Verma, R. K., Schöpf, V., Abela, E., Hauf, M., Berruecos, J. F. Z., et al. (2013). Time course based artifact identification for independent components of resting-state fMRI. Front. Hum. Neurosci. 7:214. doi: 10.3389/fnhum.2013.00214

Soldati, N., Calhoun, V. D., Bruzzone, L., and Jovicich, J. (2013a). ICA analysis of fMRI with real-time constraints: an evaluation of fast detection performance as function of algorithms, parameters and a priori conditions. Front. Hum. Neurosci. 7:19. doi: 10.3389/fnhum.2013.00019

Soldati, N., Calhoun, V. D., Bruzzone, L., and Jovicich, J. (2013b). The use of a priori information in ICA-based techniques for real-time fMRI: an evaluation of static/ dynamic and spatial/temporal characteristics. Front. Hum. Neurosci. 7:64. doi 10.3389/fnhum.2013.00064

Sui, J., He, H., Yu, Q., Chen, J., Rogers, J., Pearlson, G. D., et al. (2013). Combination of resting state fMRI. Front. Hum. Neurosci. 7:235. doi: 10.3389/fnhum.2013.00235

Welsh, R. C., Jelsone-Swain, L. M., and Foerster, B. R. (2013). The utility of independent component analysis and machine learning in the identification of the amyotrophic lateral sclerosis diseased brain. Front. Hum. Neurosci. 7:251. doi: 10.3389/ fnhum.2013.00251

Received:26 September 2013; accepted: 11 October 2013; published online: 28 October 2013. Citation: Robinson SD and Schöpf V (2013) ICA of fMRI studies: new approaches and cutting edge applications. Front. Hum. Neurosci. 7:724. doi: 10.3389/fnhum.2013.00724 This article was submitted to the journal Frontiers in Human Neuroscience.

Copyright $\odot 2013$ Robinson and Schöpf. This is an open-access article distributed under the terms of the Creative Commons Attribution License (CCBY). The use, distribution or reproduction in other forums is permitted, provided the original author(s) or licensor are credited and that the original publication in this journal is cited, in accordance with accepted academic practice. No use, distribution or reproduction is permitted which does not comply with these terms. 